\title{
Effects of polishing treatment and chemical bath deposited magnesium sulphide (MgS) thin films on ferritic stainless steel 430
}

\author{
P. Akinyemi ${ }^{1}$, O. L. Ojo ${ }^{1}$, O. T. Kolebaje ${ }^{1}$ \& C. I. Abiodun ${ }^{2}$ \\ ${ }^{I}$ Department of Physics, Adeyemi College of Education, Nigeria \\ ${ }^{2}$ Department of Physics, University of Benin, Nigeria
}

\begin{abstract}
Six flat sample plates $(7.8 \mathrm{~cm} \times 7.8 \mathrm{~cm} \times 0.1 \mathrm{~cm})$ of ferritic stainless steel 430 were polished with emery papers and gamma alumina. The films of magnesium sulphide were deposited on the sample plates using an improved chemical bath deposition (CBD) method technique at $32^{\circ} \mathrm{C}$ to $38^{\circ} \mathrm{C}$ under intense solar radiation from $2.30 \mathrm{pm}$ to $5.00 \mathrm{pm}$ respectively. The thermal emittance values of the polished and coated sample plates were determined before and after deposition of films respectively using a thermocouple potentiometer. The average thermal emittance of polished samples plates is $0.180 \pm 0.01$. Thermal emittance values of deposited magnesium sulphide $(\mathrm{MgS})$ thin film vary from 0.146 to $0.180 \pm 0.01$. Thickness of the deposited magnesium sulphide $(\mathrm{MgS})$ thin films varies from 1.790 to $9.937 \pm 0.01 \mu \mathrm{m}$. These values compared well with those obtained for selective absorbers using other deposition techniques. The chemical bath deposition techniques could be developed for deposition of the films at different temperatures with suitable deposition time to fabricate selective surfaces for solar energy applications.

Keywords: thermal emittance, chemically deposited magnesium sulphide thin films, surface solar energy collectors, ferritic stainless steel plate.
\end{abstract}

\section{Introduction}

Application of selective surface in solar energy collection was first reported in separate papers by Tabor (1955) (Gier and Dunkle [4]). Since then, several methods have been developed to fabricate a selective surface on copper, galvanized iron, aluminum and steel substrates. However, most of the selective 
absorbers have been found to suffer degradation and corrosion at high temperature [1]. Flats plates used in solar collectors for photo thermal conversion of solar energy are coated with thin layers of selective coating for optimum performance [2]. Recent investigation have evoked considerable interest in magnesium sulphide (MgS) thin films because of its applications in solar collectors, microwave shielding coatings and as sensors [3], solar absorber coating [4], solar control coating [5], electro conductive coating [6]. A spectral selective absorber has maximum absorption for solar wavelengths $(0.3$ to $2.5 \mu \mathrm{m})$ and minimum emittance of thermal wavelengths (3.0 to $30.0 \mu \mathrm{m})$ [7]. Non selective coating on the other hand exhibits high solar absorptance and high thermal emittance everywhere [8]. Black paint used in solar collectors has properties close to an ideal black surface with a solar absorptance of $95 \%$ and thermal emittance $90 \%$ [9]. Such an absorber cannot retain much heat to enhance the operating equilibrium temperature of solar collectors. Comparative values for a typical selective surface on copper are solar absorptance of $90 \%$ and thermal emittance $20 \%$.

A spectral selective surface are of interest because of the potential energy saving capabilities. The chemical bath deposition method is a simple, cheap, convenient and reproduction technique for producing high quality compound semiconductor thin films [10]. The present work reports the thermal emittance of a chemical bath deposition method, zinc sulphide $(\mathrm{ZnS})$ thin films on ferritic stainless steel 430 at room temperature of $300 \mathrm{k}$ and different deposition times for application in solar energy collectors.

\section{Experimental studies}

A plane sheet of stainless steel 430 series $\left(78 \times 78 \times 1 \mathrm{~mm}^{3}\right)$ were polished using three different abrasives grades of progressively decreasing grain sizes and $\mathrm{ABC}$ gamma polishing alumina of $0.05 \mu \mathrm{m}$ particle size until their mirror finishes were obtained. The polished sample plates were washed with distilled water, degreased with methylated spirit, rewashed with distilled water and dried.

\subsection{Preparation of the deposited bath solution}

Deposition bath solution was a mixture of different solution and volumes of reagent in $400 \mathrm{ml}$ glass beakers. The bath constituents for deposition of zinc sulphide thin films where magnesium chloride $\left(\mathrm{MgCl}_{2}\right)$ as source of cobalt ions $\left(\mathrm{Mg}^{2 \dagger}\right)$, ethylene diamine tetra-acetate (EDTA) as complexing agent, sodium hydroxide $(\mathrm{NaOH})$ and thiourea $\left[\left(\mathrm{NH}_{2}\right)_{2} \mathrm{CS}\right]$ as source of sulphide ions $\left(\mathrm{S}^{2-}\right)$.

The mass of chemical reagents for the various molar solutions was calculated from the expression

$$
\mathrm{m}=\mathrm{M} \times \mathrm{W} \times \mathrm{V} / 1000
$$

where $\mathrm{m}$ is the required molar concentration of the solution, $\mathrm{W}$ is the molar mass of the chemical salt, $\mathrm{M}$ is molarity and $\mathrm{V}$ is the volume of distilled water required. 


\subsection{Film deposition}

Six $400 \mathrm{ml}$ beakers containing different solutions of various molarities were measured in beakers. The constituents of each deposition beaker were $25 \mathrm{ml} 0.8 \mathrm{~m}$ $\mathrm{MgCl}_{2}$ solution, $16 \mathrm{ml}, 0.2 \mathrm{~m}$ EDTA solution, $12 \mathrm{ml}, 1.0 \mathrm{~m} \mathrm{NaOH}$ solution, $0.8 \mathrm{~m}$ thiourea solution and $7 \mathrm{ml}$ of distilled water. A polished stainless steel 430 series sample plate was suspended vertically in each reaction bath $32^{\circ} \mathrm{C}$ to $38^{\circ} \mathrm{C}$ under intense solar radiation from $2.30 \mathrm{pm}$ to $5.00 \mathrm{pm}$ respectively.

The equation for the chemical reaction deposition of magnesium sulphide $(\mathrm{MgS})$ thin films is:

$$
\mathrm{MgCl}_{2}+\mathrm{EDTA}+\left(\mathrm{NH}_{2}\right)_{2} \mathrm{CS}+2 \mathrm{OH}^{-} \rightarrow \mathrm{MgS}^{\downarrow}+\mathrm{CH}_{2} \mathrm{~N}_{2}+4 \mathrm{H} 2 \mathrm{O}+\mathrm{EDTA}+\mathrm{Cl}_{2}
$$

After deposition, the deposited thin films on the samples plates were raised and dried. The mass of each sample plate was measured before and after film deposition. The masses of the deposited thin films at various times are shown in table 1 below.

Table 1: $\quad$ Mass of deposited magnesium sulphide thin films.

\begin{tabular}{|l|c|c|c|c|}
\hline $\begin{array}{c}\text { Sample } \\
\text { plate } \\
\mathrm{S} / \mathrm{N}\end{array}$ & $\begin{array}{c}\text { Mass of sample } \\
\text { plate before } \\
\text { deposition }(\mathrm{g}) \\
\mathrm{M}_{1} \pm 0.01\end{array}$ & $\begin{array}{c}\text { Mass of sample } \\
\text { plate after } \\
\text { deposition }(\mathrm{g}) \\
\mathrm{M}_{2} \pm 0.01\end{array}$ & $\begin{array}{c}\text { Mass of } \\
\mathrm{MgS}(\mathrm{g}) \\
\pm 0.01\end{array}$ & $\begin{array}{c}\text { Deposition } \\
\text { time (hrs) }\end{array}$ \\
\hline 1 & 23.080 & 23.150 & 0.070 & 2.30 \\
\hline 2 & 33.710 & 33.800 & 0.090 & 3.00 \\
\hline 3 & 22.800 & 22.90 & 0.100 & 3.30 \\
\hline 4 & 33.760 & 33.870 & 0.110 & 4.00 \\
\hline 5 & 21.150 & 21.170 & 0.020 & 4.30 \\
\hline 6 & 33.680 & 33.750 & 0.070 & 5.00 \\
\hline
\end{tabular}

\subsection{Measurements}

The emittance $(\varepsilon)$ of the polished stainless steel 430 series sample plate was measured by thermocouple potentiometer before and after deposition of magnesium sulphide (MgS) thin films. The potentiometer output was obtained in millivolts $(\mathrm{mV})$ and calibrated by black standard surface. Values of the thermal emittance of magnesium sulphide thin films produced on polished and coated stainless steel 430 sample plates in table 2 were calculated from the formula:

$$
\epsilon=\frac{V_{S}}{V_{b}} \times 0.18
$$

where $V_{s}$ and $V_{b}$ represent potentiometer readings for a black standard surface and sample surface respectively. The measurements were repeated and their mean values of $\varepsilon$ obtained. The variation of thermal emittance with time is depicted in figure 1. 
Table 2: Thermal emittance of magnesium sulphide thin films produced on polished and coated stainless steel 430 sample plates from $2.30 \mathrm{pm}$ to $5.00 \mathrm{pm}$.

\begin{tabular}{|l|c|c|c|c|}
\hline \multirow{2}{*}{$\begin{array}{c}\text { Sample } \\
\text { plate } \\
\mathrm{S} / \mathrm{N}\end{array}$} & $\begin{array}{c}\text { Deposition } \\
\text { time }(\mathrm{hrs})\end{array}$ & \multicolumn{2}{|c|}{ Thermocouple reading } & $\begin{array}{c}\text { Thermal } \\
\text { emittance } \\
\boldsymbol{\varepsilon}= \pm 0.01\end{array}$ \\
\cline { 3 - 5 } & & $\begin{array}{c}\text { Black plate } \\
\mathrm{V}_{\mathrm{b}}=(\mathrm{mV}) \pm 0.01\end{array}$ & $\begin{array}{c}\text { Sample plate } \\
\mathrm{V}_{\mathrm{s}}=(\mathrm{mV}) \pm 0.01\end{array}$ & \\
\hline 1 & 2.30 & 98.00 & 80.00 & 0.146 \\
\hline 2 & 3.00 & 92.00 & 94.00 & 0.164 \\
\hline 3 & 3.30 & 98.00 & 90.00 & 0.165 \\
\hline 4 & 4.00 & 96.00 & 90.00 & 0.168 \\
\hline 5 & 4.30 & 97.00 & 94.00 & 0.176 \\
\hline 6 & 5.00 & 120.00 & 100.00 & 0.180 \\
\hline
\end{tabular}

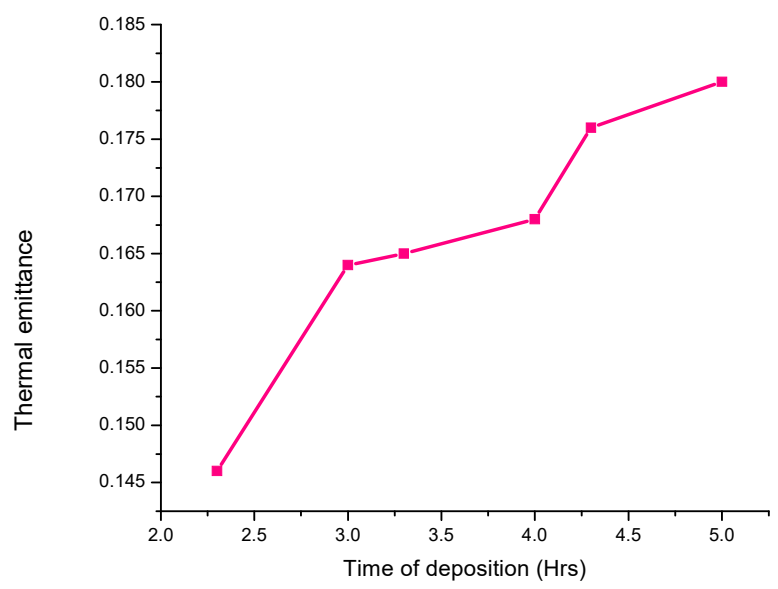

Figure 1: Variation of thermal emittance with time.

\subsection{Measurement of thickness}

Film thickness was calculated from the formula

$$
\mathrm{t}=\mathrm{m} / 2 \mathrm{dA}
$$

where $\mathrm{m}$ is the mass of magnesium $(\mathrm{MgS})$ films deposited on a sample plate, obtained from the difference in mass of each sample plate before and after film deposition. $A$ is the area of the film on a sample plate and $\mathrm{d}=4.10 \mathrm{~g} / \mathrm{cm}^{3}$ for 
magnesium sulphide thin film. Values of thickness of magnesium sulphide thin films produced is depicted in table 3 below and the variation of film thickness is with time is shown in figure 2.

Table 3: $\quad$ Film thickness of deposited magnesium sulphide thin films.

\begin{tabular}{|c|c|c|c|c|c|}
\hline $\begin{array}{c}\text { Length } \\
(\mathrm{cm})\end{array}$ & $\begin{array}{c}\text { Breadth } \\
\mathrm{b}(\mathrm{cm})\end{array}$ & $\begin{array}{c}\text { Area } \\
(\mathrm{cm})^{2}\end{array}$ & $\begin{array}{c}\text { Mass of } \\
\text { film }(\mathrm{g})\end{array}$ & $\begin{array}{c}\text { Film } \\
\text { thickness t } \\
(\mu \mathrm{m})\end{array}$ & $\begin{array}{c}\text { Time } \\
\text { deposition } \\
(\mathrm{hrs})\end{array}$ \\
\hline 7,700 & 2,000 & 15,400 & 0.700 & 1,790 & 2.30 \\
\hline 7,500 & 2,000 & 15,000 & 0.090 & 7,317 & 3.00 \\
\hline 7,500 & 1,800 & 13,000 & 0.100 & 9,033 & 3.30 \\
\hline 7,500 & 2,000 & 15,000 & 0.110 & 9,937 & 4.00 \\
\hline 7,500 & 1,800 & 13,000 & 0.020 & 5,543 & 4.30 \\
\hline 7,500 & 1,800 & 13,000 & 0.070 & 6,323 & 5.00 \\
\hline
\end{tabular}

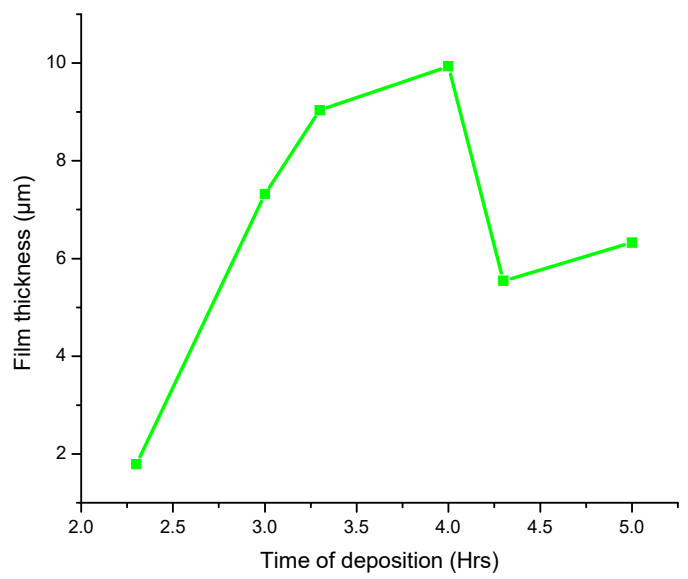

Figure 2: Variation of film thickness with time.

\section{Discussion}

The results of thermal emittance of polished ferritic stainless steel 430 sample plates and deposited magnesium sulphide thin films on the sample plates are shown in table 2. Average thermal emittance values for the coated sample plates increase slowly from 0.146 to $0.180 \pm 0.01$. These values compare well with the thermal emittance values of $0.18 \pm 0.01$ for chemically oxidized stainless steel AISI 321 [7]. The coating helps to modify the microstructure and composition of 
the absorber so as to provide high absorbance for the wavelength range $0.3-2.0$ $\mu \mathrm{m}$ [11]. The masses of the deposited thin films of magnesium sulphide vary from 0.02 to $0.11 \mathrm{~g}$ depending on deposition time as shown in Table 1 . The thickness of deposited thin films vary from 1.790 to $9.937 \pm 0.01 \mu \mathrm{m}$ depending on deposition times as shown in table 3 and figure 2 respectively. This technique of deposition could be used at both high and low temperatures with a suitable deposition time to produce selective absorbers for solar thermal applications. The thickness of such film produced could be hardened to withstand adverse weather conditions while at the same time retaining low thermal emittance. The selective absorbers could be employed in poultry production for construction of solar chicks' brooders to provide heat to very young chicks which have no insulating feathers against adverse cold weathers condition during the day. This could also help to reduce high cost of energy consumption through the use of lamps stoves, electric bulbs and heaters.

\section{Conclusion}

Magnesium sulphide (MgS) thin films were deposited on polished ferritic stainless steel 430 sample plates using chemical bath method at room temperature and different deposition times. Magnesium sulphide $(\mathrm{MgS})$ thin films were produced at $32^{\circ} \mathrm{C}$ to $38^{\circ} \mathrm{C}$ under intense solar radiation from 12.00am to $5.00 \mathrm{pm}$. The average thermal emittance of the polished stainless steel 430 sample plates is $0.16 \pm 0.01$. The values compare favourably with a thermal emittance value of 0.13 to $0.17 \mu \mathrm{m} \pm 0.01$ for polished stainless steel AISI 321 [7, $12,13]$. The thermal emittance of the coated sample plates increases slowly depending on deposition time from 0.15 to $0.19 \mu \mathrm{m} \pm 0.01$ for chemically oxidized stainless steel AISI 321 for use in solar energy application [9]. The masses of the deposited Magnesium sulphide thin films vary from 0.02 to $0.11 \mathrm{~g}$ depending on deposition times and thickness of the deposited thin films vary from 1.790 to $9.40 \pm 0.01 \mu \mathrm{m}$ depending on deposition time. The values of thermal emittance obtained at different deposition times for the deposited magnesium sulphide thin films compare favorably with obtained for selective surfaces used in solar energy collectors.

\section{References}

[1] Berzoni J.T. (1998). Coating for Solar collector's symposium; American Electroplaters Society, G.A

[2] Chouldhury, C. and Schgal, II.K. (1993). Solar Energy, 30, 291.

[3] Daletsiki T. (1997). Galiotekhnika, 15, 1.

[4] Gier, G.T. and Dunkle, R.V. (2000). Selective spectral characteristics as an important factor in the efficiency of solar collectors, Trans. Conf. on the Use of Solar Energy.

[5] Granziera, F. (2002). Coloured stainless steels, Aluminum Anodizer Pty Ltd., Metal Australasia, 211. 
[6] McDaniel, D.K. (2006). The sum our future energy source, Wiley, New York.

[7] Sharma, V.C and Hutchins, M.G. (2006). Radioactive selectivity and the oxidation of stainless steels, Proc ISES, Altlanta, G.A., 3, 1940.

[8] Sharma, V.C. (2007). Effect of polishing treatment and thermal oxidation on the total hemispherical thermal emittance of austentic stainless steel, AISI 321, Energy, 7, 607.

[9] Sharma, V.C., Sharma, A. and IIenikhena, P.A. (2007) Energy, 13(10), 749-754.

[10] Smith, G.B. and Ignatiev, A. (2007). Sol. Energy Matter. 2, 461.

[11] Daleski, G.S. Karpenko, I.V. Koltun, M.M., Karpukhin, V.M., Ryabikov, I.V. and Tykvenko. (1997). Geliotekhnika, 15, 1.

[12] Akinyemi P., Kolebaje O.T., Adenodi R.A., Abiodun C.I. (2014). Thermal Emittance of solar energy assisted chemical bath deposited zinc sulphide thin films on stainless steel 430, National Association of Mathematical Physics, Vol. 27, pp. 623-626.

[13] Ilenikhena, P.A., Alli, N., Ofili, J.N. (2007). Effects polishing treatment and chemically deposited Magnesium Chloride $(\mathrm{MgCl} 2)$ Thin Films on thermal emittance of stainless steel series 430, Solar Energy, vol. 18, pp. 58-62.

[14] Berzoni J.T. (1976). Coating for collectors symposium; American Electroplates Society, G.A. 